\title{
EFFECT OF ENDOCRINE DISRUPTOR PHYTOESTROGENS ON THE IMMUNE SYSTEM: PRESENT AND FUTURE
}

\author{
GYÖRGY CSABA* \\ Department of Genetics, Cell- and Immunobiology, Semmelweis University, \\ Budapest, Hungary
}

(Received: 10 October 2017; accepted: 15 November 2017)

Endocrine disruptors (EDs) are bound by steroid receptors, have steroid-like effects, and by this, negatively influence hormone-regulated processes. Phytoestrogens, which are consumed in enormously high amount by man, are also EDs; however, in contrast to industrial or communal EDs, in some cases have beneficial effects. As immune cells have steroid (first of all, estrogen) nuclear and plasma membrane receptors, which bind phytostrogens (genistein, daidzein, etc.), the development, lifespan, and function of them are deeply influenced by phytoestrogens. They can provoke perinatal faulty hormonal imprinting with lifelong consequences. However, faulty imprinting can be developed not only perinatally but also in other critical periods of life, as weaning, adolescence, and even in continuously dividing cells (e.g., hemopoietic cells) during the whole life. This means that the phytoestrogens could cause direct - instant or long-lasting steroid effects and durable imprinting effects. As the effect of hormonal imprinting is epigenetically inherited, the phytoestrogen's effects appear in the progeny generations, and the generationally repeated disruptor effects will be different from the present ones. This could also be manifested in the amount, type, and appearance of autoimmune diseases. The consumption of soy is enormously growing, and its immune effect is extended. As the immune system influences basic physiological processes, it seems likely that evolutionary alterations will be observed. In this case, some phytoestrogens will be needed for the normal life of man, as it happened in the case of vitamins A and D, which are already lifeimportant exohormones. However, quantitatively or qualitatively enormous amount of phytoestrogens will cause pathological and epigenetically inherited alterations.

Keywords: genistein, daidzein, hormonal imprinting, exohormones, evolution, autoimmunity

*E-mail: csaba.gyorgy@med.semmelweis-univ.hu 


\section{Introduction}

A significant problem of our age is that the environment of man is filled with hormone-like molecules or such molecules which have other structures, however, are able to bind to steroid hormone receptors. These are the endocrine disruptors (EDs), which can influence the transmission of normal hormonal messages, simulating the real hormones or inhibiting their binding. Most of the EDs are human (industrial, agrotechnical, or communal) products; however, there are also natural EDs contained by plants that are consumed by human beings. The most important forms of these latter are the phytoestrogens.

The well-known disruptor effects of the aforementioned molecules are manifested in the sexual area, the thyroid gland, the brain, and the immune system.

\section{General (Non-Immune) Effects of Phytoestrogens}

Phytoestrogens are plant steroids, which include isoflavones, lignans, coumestanes, stilbenes, and the flavonoids, such as quercetin and kaempferol [1]. From human point of view, the isoflavones seem to be the most important. They have a special position among EDs, as

1. in contrast to other (such as industrial) disruptors, they enter into the human organism purposely as men, although knowing their properties, consume them as components of food;

2. considering point 1 , their amount entering into human organism is higher than the other ones;

3. they can enter into the human organism during the most critical developmental periods;

4. they are in "human use" since 1,000 years; and

5. in contrast to other disruptors in addition to dangerous impacts, they have proved beneficial effects in the case of different diseases.

The most studied phytoestrogens are the isoflavones of soy bean, genistein (GS), and daidzein. GS and the female sexual hormone estradiol have similar structure and this phytoestrogen can be bound by estrogen receptors ER alpha and beta, mainly by the latter $[2,3]$. These receptors can be found in many systems and organs, including the cells of the immune system. The binding of GS to the ER beta receptor is as strong as that of beta estradiol and by this, GS can influence the development and function of these systems, or organs. GS's effect is outstanding in the case of the reproductive system [4], where acting during the development can cause cryptorchidism and hypospadias as well as functional alterations (such as infertility). There are strong grounds for suspecting that its chronical use is responsible for 
stepping forward of menarche. Its long-lasting use can cause the weakening of thyroid function (hypothyreosis) [5] - as thyroid hormone receptors are belonging to the steroid receptor superfamily - and also negatively influences the cognitive function of the brain; however, many positive effects are also known. The Asian population which consumes soy food since 3,000 years have higher rates of thyroid, esophageal, pancreatic, stomach, and liver cancers but lower rate of breast, prostate, and colon cancers [6]. Effects similar to GS are provoked by the less-studied daidzein.

\section{Immune Effects of EDs in General}

During the evolution, the steroid receptors first appeared in vertebrates [7]. The first steroid receptor was an estrogen receptor (second was progesterone) and all other steroid receptors were evolved from them [8-10]. These - supplemented with other nuclear receptors (e.g., thyroid hormone receptor, retinoid receptor, peroxysome proliferetor activated receptor, etc.) - compose the steroid (nuclear) receptor superfamily. It is known that immune cells have estrogen receptors and some of them have other steroid receptors also. These receptors (ER alpha and ER beta) are localized in the nucleus. However, there are also membrane-localized estrogen receptors, which can provoke instant response [11-13]. In addition, estrogen is the most ancient hormone. Estrogens affect the development and organization of immune cells and organs and modulate immunological responses. In the absence of ER alpha, ERKO mice have hypoplastic thymus and spleen and increased amount of immature thymocytes [14]. Considering these facts, the immune effect of EDs, which mimic steroids, cannot be surprising [15]. EDs can act by binding to the receptors and stimulating their action or also by binding to the receptors and inhibiting the binding and action of the natural hormone (estradiol) [16].

EDs are influencing the synthesis of immunoglobulins, cytokines, and inflammatory mediators [17] and immune cell activation as well as the cell's survival are exerted by them [18]. This means that the humoral immunity is seriously influenced. This property is manifested by the decrease of immunity, provocation of inflammation, and allergic diseases as well as induction of autoimmune diseases [19]. They help the manifestation of cancerous alterations.

\section{Immune Effects of Phytoestrogens}

Facts

GS treatment of adult mice caused dose-dependent decrease of the thymus weight and decreased the number of thymocytes $(2,1,10)$. This decrease could be 
about $80 \%[20,21]$. In other experiment, GS also decreased the number of thymocytes, and this reduction was $86 \%$ [20]. In human soy-fed infants, marked thymic atrophy was observed [20]. GS influences cytokine production and secretion and activate NK cells. There were experiments in which GS selectively enhanced or decreased the immune activity [20,22]. Sometimes, high isoflavone diet caused enhanced and, in other case, decreased inflammatory effects in the F0 and $\mathrm{F} 1$ generations. About $46 \%-67 \%$ decrease in deleted-type hypersensitivity was observed in footpad test [23]. GS enhances the cytotoxic response mediated by NK and cytotoxic $\mathrm{T}$ cells and the cytokine production from T cells [16]. GS also reduced the number of developing $\mathrm{CD}^{+}$and $\mathrm{CD} 8^{+}$thymocytes [20, 24].

Cell-mediated immunity is suppressed by GS [23]. Its high concentrations inhibit leukotriene B4, interleukins (ILs) and interleukin receptors [25], T cellmediated tumoricidal activity, leukocyte adherence, T-cell motility, and also inhibits the activation of NK cells. These effects are reversible [23]. GS can also increase thymic size [26], if the treatment was done perinatally. However, prenatal exposure to soy isoflavones causes immunosuppression in adult age [27]. In adult mice, $200 \mathrm{mg} / \mathrm{kg}$ dose of GS leads to near total elimination of thymocytes [20] and $8 \mathrm{mg} / \mathrm{kg}$ reduced the antibody formation by more than $50 \%$.

In man, gamma globulins and immunoglobulins were decreased in soy-fed infants and also T-cell functions show impairment. Reduced levels of antibodies against diseases (polio, tetanus, diphteria, and pertussis) [28] were observed. Cell-mediated immunity was decreased [23]. There are both increasing and decreasing effects [21]. GS exposure perinatally (during lactation) increases the thymus masses and decreases $\mathrm{CD} 4^{-} \mathrm{CD} 8^{-}$thymocytes in adult age [26]. GS induces thymus involution, employed developmentally [29].

Daidzein enhanced the mice peritoneal macrophages and the weight of thymus [18]. In mice, it helped the activation of spleen cells in producing antibodies to sheep erythrocytes [18]. High doses of daidzein stimulated nonspecific immunity in mice (increase of phagocytic response by peritoneal macrophages and thymic weight) and in general activates humoral immunity [30]. Thymic weight was increased and phagocytic avtivity was enhanced as well as the number of circulating lymphocytes under the effect of daidzein treatment [30].

Soy isoflavones stimulated allergic reactions [31]. Female mice were more sensitive to isoflavones than males [18]. They were beneficial in chronic health disorders, by regulating immune response [19]. IL-1 $\alpha$ and IL-2 were suppressed, IL-4 was stimulated by dietary soy phytoestrogens in rats, and total leukocyte count was also increased [32]. In case of chronic bacterial infection (Mycobacterium avium) in mice, soy diet influences the production of key regulatory cytokines [33]. The discrepancy in some results can be explained by different targets, different receptors [34], and immune cell dependency. 
The isoflavones (GS and daidzein) suppress dendritic cell maturation and subsequent effector cells' functions (immune sensitizations) in human cases [35].

\section{Phytoestrogens and Autoimmunity}

Soy-containing commercial rodent diet influences cytokine production and accelerates renal damage in autoimmune Murphy Roths Large/lymphoproliferative (MRL/lpr) mice [36, 37]. The effects are mediated by suppression of inflammatory pathways [38]. GS protects the pancreas from autoimmune destruction and by this, from developing type-1 diabetes. Oral dosing of the phytoestrogen reduced the incidence and increased the time of onset in female non-obese diabetic mice [39]. In Hashimoto thyroiditis patients, likely by regulating Th1 cells improves thyroid function [40]. GS, by modulating anti-inflammatory cytokines, ameliorated the clinical symptoms in experimental autoimmune encephalomyelitis, a mice-model of sclerosis multiplex [41]. In early phase of the disease, it reduced neural demyelination, suppressed the production of interferon (INF)- $\gamma$, and enhanced IL-10 secretion in splenocytes and the brain. It also reduced IL-12 and TNF- $\alpha$ secretion of splenocytes and suppressed proliferation and cytotoxicity of $\mathrm{T}$ cells [42].

Perinatal exposure of GS causes life-long effects to the immune system. In 70-day-old rats, thymus of the perinatally treated male rats were higher the percentages of $\mathrm{CD} 4^{+} \mathrm{CD} 8^{+}$thymocytes, and $\mathrm{CD} 8^{+}$splenocytes and total $\mathrm{T}$ cells in the spleen were also higher in GS-exposed males than that of control ones. In contrast to these results, the amount of $\mathrm{CD}^{-}{ }^{-} \mathrm{CD} 8^{-}$thymocytes was lower [26].

Daidzein reduced the extent of demyelination and severity in case of allergic encephalomyelitis. After the onset of the disease, treatment with high doses of reduced INF- $\gamma$ and IL-12 secretion enhanced IL-10 production, suppressed lymphocyte proliferation, and decreased cytotoxicity [43]. Daidzein, by enhancing efferocytotic capability of macrophages, also reduces in case of autoimmune and inflammatory diseases [44].

Dietary isoflavones worsen the development of glomerulonephritis in female MRL/lpr mice, which have systemic lupus erythematosus, by enhanced immune complex protein deposition and altered cellular infiltration [45].

Dietary GS, in less concentration than it is in soy-fed infants, causes thymic atrophy and immune abnormalities [20].

Pre-menopausal women's systemic lupus erythematosus incidence is extremely higher related to men of the same age range (9:1) and after menopause, it is 5:1. This is in the preadolescent population 3:1 [46].

Coumoestrol, which is found in some plants and Chinese medicinal herbs, decreases thyroid-specific autoantibodies and supresses autoimmune thyroiditis [47]. 


\section{Conclusions}

Considering the not at all complete list of data shown above, it can be declared that phytoestrogens influence the immune system; however, the direction and strength of their effects are dependent on many factors as the species, gender, organ or cell, duration or life-phase of exposure, concentration, etc. Although the phytoestrogens are present in the animal (human) organisms in higher concentrations than natural hormones, their effects seem to be less. As an example, in infants fed by soy infant formula, the isoflavone concentration is 13.000 to 22.000 higher (about the amount that is caused by five anticoncipient tablets) than estradiol plasma concentration; however, their steroid hormonal effect is less effective than that of the natural hormone [48]. Almost all of this extreme amount of phytoestrogen is present in inactive form and in the intestinal tract will be transformed to a biologically active form. After that, it can disturb the effects of natural hormones, causing faulty hormonal imprinting [49-51] with late, life-long alteration of physiological processes, sex organ development, thyroid function, brain maturation, and immune response included [52, 53]. The hormonal imprinting is absolutely needed and physiological around birth in case of the first encounter between the own hormones of the newborn and the developing receptors and this is disturbed (cheated) by related molecules (synthetic hormones, environmental pollutants, and EDs, etc.) $[52,54,55]$ or are influenced by quantitative changes of physiological molecules.

Faulty hormonal imprinting of the immune system can develop, as hormones and hormone receptors are present in the immune cells $[51,56]$. These receptors are reacting to steroid or thyroid hormones, as well as to peptide ones (endorphin, thyroid-stimulating hormone, gonadotropic hormone, etc. [51, 57-59]). The steroid hormone receptors are the members of steroid receptor superfamily and seem to be very important from this aspect. This group includes the sex hormone receptors, thyroid hormone receptors, adrenal gland steroid hormone (glucocorticoid and mineralocorticoid) receptors, vitamin $\mathrm{D}$ receptors, and retinoid receptors, all of them influencing the development, the lifespan, and function of immune system [60-64]. The hormones, binding to the receptors, can influence each immune cells or specifically one type of them (e.g., thyroid hormone effects on macrophages [63]). The receptors are present in the nucleus; however, some of them can be found as plasma membrane receptors [65]. This is very important as the membrane-bound receptors are responsible for the instant response of the cells and also there is a possibility of combined (nuclear and membrane receptor transmitted) response. As these receptors belong to the same hormone family, there is a possibility of overlap between the members in critical periods of life, when the developmental window 
for hormonal imprinting is open. This is first of all the perinatal critical period and the most important - normal or faulty - hormonal imprinting taking place in that time. The normal - physiological - imprinting is absolutely needed for the normal binding of receptors and hormones for life, the faulty inmprinting converts it to a pathological one. As phytoestrogens are able to bind to the estrogen receptors ( $\alpha$ or $\beta$ ) of immune cells, they can disturb the further development and function of these cells, lifelong. It is known that glucocorticoid receptors are altered by neonatal phytoestrogen imprinting [66] and sexual behavior of rats is also influenced [55] however, unknown is the effect on immunity, however, it can be supposed. In addition, the effect of faulty hormonal imprinting is transmitted epigenetically to the progeny generations, at least up to the third one $[67,68]$. The methylation pattern, which has a basic role on epigenetic inheritance, is deeply influenced by phytoestrogens [69-72]. This means that the phytoestrogen consumption of the next generations will cause different effects on steroid-directed functions related to the present ones, as the new imprinting alters receptors, which were already influenced in the previous generations.

As there are many members of the steroid receptor superfamily, these receptors can be found in the cells of the immune system; in addition, there are nuclear and membrane bound forms alike, sometimes controversial effects of phytoestrogens can be explained. This goes not only to the case of perinatal imprinting but also for adult's exposure. Because in the real world imprinters are not always effect alone, but in the presence of other imprinter(s) [66], this can change the strength and direction of the effect.

Although the faulty imprinting effect seems most dangerous in the perinatal period, it is not ineffective during the whole life. In later phases, the effect of phytoestrogenes is manifested directly as a steroid effect, stimulating or inhibiting the immune system and the effect is likely reversible [23]. However, hormonal imprinting is executed not only perinatally but also later at weaning, during adolescence, and in continuously dividing (differentiating) cells for life [49, 69]. This means that phytoestrogens are able to alter physiological and pathological processes (as immunity and autoimmunity) [56,73] directly, as a steroid effect, or can provoke imprinting at any phase of life, however, with different strength. In addition, minimal dose of them can provoke imprinting which also transmitted to the progenies, as hormonal imprinting - as it was mentioned before - is inherited epigenetically.

The human consumption of soy started about 3,000 years ago by the Asian population; however, it bursted into Europe (and America) only in the last century. Since this time, its per capita consumption gradually increased: between 1961 and 1972, the growth rate was 3.5\% and between 2009 and 2010, it was 5.9\%. Only in 
2005, according to Greenpeace, about 1.2 million hectares of soy was planted in Brazilian rainforests [74]. Infants are consuming soy in the formula, whereas adults in tofu, miso, ice cream, cold meat, etc. And also in the meat of animals (pork, chicken, etc.) as farm animals are fed also with soy, as about $90 \%$ of of 200 million tonnes/year produced worldwilde, is used to feed animals [75].

Knowing that in the Asian population, soy did not cause special diseases, and phytoestrogens are sometimes believed harmless. However, the construction of the Asian people is different, related to the European (American) ones and it can be supposed that this is due to the different nourishing during millenials. From this aspect, the immune system could not be an exception. The time of menarche is earlier in the Asian populations and today, since the extreme consumption of phytosteroids in Europe, similar tendency can be observed [76, 77]. There are not exact evidences to similar alterations in case of immune system; however, it can be strongly supposed.

As it was shown, in contrast to other (industrial and communal) EDs, phytoestrogens also have beneficial effects on the function of immune system. However, it is not cleared when and in what doses are beneficial and when dangerous. The results of animal experiments are contradictory and cannot be securely projected to human beings. There is a similar situation in the case of autoimmunity where effects, provoking disease can be found as well, as such, which improves the symptoms. The human observations are also controversial, so it is difficult to declare definite opinion.

In case of human autoimmune diseases, phytoestrogens could have beneficial effects if they are used as a therapy and there is a similar situation in the case of different tumors. These latter's effects are transmitted through the immune system, the activation or suppression of which is the basis of the improvement. Although the immunomodulatory role of sex steroids was demonstrated in the pathogenesis of systemic lupus erythematosus, rheumatoid arthritis, and multiple sclerosis [78], the scientific background is not cleared as well as the background of phytoestrogen's beneficial effects.

Most of the EDs are entering into human organism as we are not able to avoid them. They are present in the environment as products of industrial activity which helps to improve our life or as products of agrotechnic, which helps to satisfy our nourishment, as well as in the form of drugs, water and air-pollutants, or nutrient supplements [79-81]. This means that they are consumed involuntarily. Phytoestrogens are consumed as side products in nutrients (fruits as plum, pear, vegetables as beans, sprouts, cabbage, spinach, grains, hops, garlic, onion, wine, tea, and outstandingly soy) and are consumed wilfully, although knowing their effects. This means that our immune system is influenced continously by them without knowing the direction and the direct target of phytoestrogen bombardment. 
The mass consumption of phytoestrogens by man could cause evolutionary alterations [82-84]. It is clear that the Caucasian and Asian men are different from many points of view. There are hormonal differences, which are manifested as the time of menarche and menopuse, as the start of adolescence, etc. There are not exact comparisons in case of immunity; however, it seems to be sure that differences can also be observed and they are likely ascribed to the three millenial phytoestrogen consumption. Now in Europe and America, the soy consumption is high and enormously growing and the signs of alterations in hormone-regulated indexes are shown. Considering the hormonal imprinting and its epigenetic inheritance [67, 69], the gradual changes of immune parameters by it are not precluded. The amount and appearance of autoimmune diseases can be changed in the progeny generations as well, as the reaction of the patients to medicaments. This means, that later phytoestrogens would be classified as exohormones, as happened in case of vitamins A and D [79, 85, 86], which are absolutely needed for the normal life of human beings.

\section{Conflict of Interest}

None.

\section{References}

1. Moutsatsou, P.: The spectrum of phytoestrogens in nature: Our knowledge is expanding. Hormones 6, 173-193 (2007).

2. Mueller, S. O., Simon, S., Chae, K., Metzler, M., Korach, K. S.: Phytoestrogens and their human metabolites show agonistic and antagonistic properties on estrogen receptor $\alpha(E R \alpha)$ and ER $\beta$ in human cells. Toxicol Sci 80, 14-25 (2004).

3. Casanova, M., You, L., Gaido, K. W., Archibeque-Engle, S., Janszen, D. B., Heck, H. A.: Developmental effects of dietary phytoestrogens in Sprague-Dawley rats and interactions of genistein and daidzein with rat estrogen receptors alpha and beta in vitro. Toxicol Sci 51, 236-244 (1999).

4. Patisaul, H. B., Adewale, H. B.: Long-term effects of environmental endocrine disruptors on reproductive physiology and behavior. Front Behav Neurosci 3, 1-29 (2009).

5. Tran, L., Hammuda, M., Wood, C., Xiao, C. W.: Soy extracts suppressed iodine uptake and stimulated the production of autoimmunogen in rat thyrocytes. Exp Biol Med 238, 623-630 (2013).

6. Hwang, K. A., Choi, K. C.: Anticancerogenic effects of dietary phytoestrogens and their chemopreventive mechanism. Nutr Cancer 67, 796-783 (2015).

7. Trimel, S.: Estrogen emerges as most ancient of all hormones. Columbia Univ Rec 26, 1-4 (2001).

8. Thornton, J. W.: Evolution of vertebrate steroid receptors from an ancestral estrogen receptor by ligand exploitation and serial genome expansions. Proc Natl Acad Sci U S A 98, 5671-5676 (2001). 
9. Fox, J. E.: Chemical communication threatened by endocrine disrupting chemicals. Environ Health Perspect 112, 648-653 (2004).

10. Eick, G. N., Thornton, J. W.: Evolution of steroid receptors from an estrogen-sensitive ancestral receptor. Mol Cell Endocrinol 334, 31-38 (2011).

11. Kovats, S.: Estrogen receptors regulate innate immune cells and signaling pathways. Cell Immunol 294, 63-69 (2015).

12. Schneider, A. E., Kárpáti, E., Schuszter, K., Tóth, E. A., Kiss, E., Kulcsár, M., László, G., Matko, J.: A dynamic network of estrogen receptors in murine lymphocytes: Fine-tuning the immune response. J Leukoc Biol 96, 857-872 (2014).

13. Seiki, K., Sakabe, K.: Sex hormones and the thymus in relation to thymocyte proliferation and maturation. Arch Histol Cytol 60, 29-38 (1997).

14. Erlandsson, M. C., Ohlsson, C., Gustafsson, J. A., Carlsten, H.: Role of oestrogen receptors $\alpha$ and $\beta$ in immune organ development and in oestrogen-mediated effects on thymus. Immunology 103, 17-25 (2001).

15. Morito, K., Hirose, T., Kinjo, J., Hirakawa, T., Okawa, M., Nohara, T., Ogawa, S., Inoue, S., Muramatsu, M., Masamune, Y.: Interaction of phytoestrogens with estrogen receptors $\alpha$ and $\beta$. Biol Pharm Bull 24, 351-356 (2001).

16. Sakai, T., Kogiso, M.: Soy isoflavones and immunity. J Med Invest 55, 167-173 (2008).

17. Kuo, C.-H., Yang, S.-N., Kuo, P.-L., Hung, C.-H.: Immunomodulatory effects of environmental endocrine disrupting chemicals. Kaohsiung J Med Sci 28, 537-542 (2012).

18. Chalubisnski, M., Kowalski, M. L.: Endocrine disrupters - Potential modulators of the immune system and allergic response. Allergy 61, 1326-1335 (2006).

19. Masilamani, M., Wei, J., Sampson, H. A.: Regulation of the immune response by soybean isoflavones. Immunol Res 54, 95-110 (2012).

20. Yellayi, S., Naaz, A., Szewczikowski, M. A., Sato, T., Woods, J. A., Chang, J., Segre, M., Allred, C. D., Helferich, W. G., Cooke, P. S.: The phytoestrogen genistein induces thymic and immune changes: A human health concern? Proc Natl Acad Sci U S A 99, 7616-7621 (2002).

21. Cooke, P. S., Selvaraj, V., Yellayi, S.: Genistein, estrogen receptors, and the acquired immune system. J Nutr 136, 704-708 (2006).

22. Guo, T. L., White, K. L., Jr., Brown, R. D., Delclos, K. B., Newbold, R. R., Weis, C., Germolec, D. R., McCay, J. A.: Genistein modulates splenic natural killer cell activity, antibody-forming cell response, and phenotypic marker expression in $F(0)$ and F (1) generation of Sprague-Dawley rats. Toxicol Appl Pharmacol 181, 219-227 (2002).

23. Yellayi, S., Zakroczymski, M. A., Selvaraj, V., Valli, V. E., Ghanta, V., Helferich, W. G., Cooke, P. S.: The phytoestrogen genistein suppresses cell-mediated immunity in mice. J Endocrinol 176, 267-274 (2003).

24. Ganai, A. A., Farooqi, H.: Bioactivity of genistein: A review of in vitro and in vivo studies. Biomed Pharmacother 76, 30-38 (2015).

25. Polkowski, K., Mazurek, A. P.: Biological properties of genistein. A review of in vitro and in vivo data. Acta Pol Pharm 57, 135-155 (2000).

26. Klein, S. L., Wisniewski, A. B., Marson, A. L., Glass, G. E., Gearhart, J. P.: Early exposure exerts long-lasting effects on the endocrine and immune system in rats. Mol Med $\mathbf{8}$, $742-749$ (2002). 
27. Ebaid, H. M., Elgawish, R. A., Abdelrazek, H. M., Gaffer, G., Tag, H. M.: Prenatal exposure to soy isoflavones altered the immunological parameters in female rat. Int $\mathrm{J}$ Toxicol 35, 274-283 (2016).

28. Zoppi, G., Gasparini, R., Montovanelli, F., Crovari, P.: Diet and antibody response to vaccination in healthy infants. Lancet 322, 11-14 (1983).

29. Selvajar, V., Bunick, D., Finnigan-Bunick, C., Johnson, R. W., Wang, H., Liu, L., Cooke, P. S.: Gene expression profiling of $17 \beta$-estradiol and genistein effects on mouse thymus. Toxicol Sci 87, 97-112 (2005).

30. Zhang, R., Li, Y., Wang, W.: Enhancement of immune function in mice fed high doses of soy daidzein. Nutr Cancer 29, 24-28 (1997).

31. Han, D., Denison, M. S., Tachibana, H., Yamada, K.: Effects of estrogenic compounds on immunoglobulin production by mouse splenocytes. Biol Pharm Bull 25, 1263-1267 (2002).

32. Shalaby, A., Elgawish, R. A. R.: Influence of dietary soy phytoestrogens on cytokine production and immunoglobulin in ovariectomized rats. J Adv Chem Eng Biol Sci 2, 91-96 (2015).

33. Curran, E. M., Judy, B. M., Newton, L. G., Lubahn, D. B., Rottinghaus, G. E., Macdonald, R. S., Franklin, C., Estes, D. M.: Dietary soy phytoestrogens and ER $\alpha$ signalling modulate interferon gamma production in response to bacterial infection. Clin Exp Immunol 135, 219-225 (2004).

34. Sirothkin, A. V., Harrath, A. H.: Phytoestrogens and their effects. Eur J Pharmacol 741, 230-236 (2014).

35. Wei, J., Bhatt, S., Chang, L. M., Sampson, H. A., Masilamani, M.: Isoflavones, genistein and daidzein, regulate mucosal immune response by suppressing dendritic cell function. PLoS One 7, e47979 (2012).

36. Zhao, J. H., Sun, S. J., Horiguchi, H., Arao, Y., Kanamori, N., Kikuchi, A., Oguma, E., Kayama, F.: A soy diet accelerates renal damage in autoimmune MRL/p-IprIpr mice. Int Immunopharmacol 5, 1601-1610 (2005).

37. Edwards, M. R., Dai, R., Heid, B., Cecere, T. E., Khan, D., Mu, Q., Cowan, C., Luo, X. M., Ahmed, S. A.: Commercial rodent diets differentially regulate autoimmune glomerulonephritis, epigenetics and microbiota in MRL/Ipr mice. Int Immunol 29, 263-276 (2017).

38. Tezuka, H., Imai, S.: Immunomodulatory effects of soybeans and processed soy food compounds. Recent Pat Food Nutr Agric 7, 92-99 (2015).

39. Guo, T. L., Germolec, D. R., Zheng, J. F., Kooistra, L., Auttachoat, W., Smith, M. J., White, K. L., Elmore, S. A.: Genistein protect female nonobese diabetic mice from developing type 1 diabetes when fed a soy- and alfalfa-free diet. Toxicol Pathol 43, 435-448 (2015).

40. Zhang, K., Wang, Y., Ma, W., Hu, Z., Zhao, P.: Genistein improves thyroid function in Hashimoto thyroidits patients through regulating Th1 cytokines. Immunobiology 222, 183-187 (2017).

41. De Paula, M. L., Rodrigues, D. H., Teixeira, H. C., Barsante, M. M., Souza, M. A., Ferreira, A. P.: Genistein down-modulates pro-inflammatory cytokines and reverses clinical signs of experimental autoimmune encephalomyelitis. Int Immunopharmacol 8, 1291-1297 (2008).

42. Jahromi, S. R., Arrefhosseini, S. R., Ghaemi, A., Alizadeh, A., Sabethgadam, F., Togha, M.: Effect of oral genistein administration in early and late phases of allergic encephalomyelitis. Iran J Basic Med Sci 17, 509-515 (2014). 
43. Razeghi Jahromi, S., Arrefhosseini, S. R., Ghaemi, A., Alizadeh, A., Moradi Tabriz, H., Togha, M.: Alleviation of experimental allergic encephalomyelitis in C57BL/6 mice by soy daidzein. Iran J Allergy Asthma Immunol 13, 256-264 (2014).

44. Yen, J. H., Yang, D. J., Chen, M. C., Yi-Ying, W., Hsieh, Y. F., Cheng, Y. M., Huang, W. N., Szondy, Z., Tsay, G.: Daidzein enhances efferocytosis vis transglutaminase 2 and augmentation of Rac1 activity. Mol Immunol 60, 135-142 (2014).

45. Edwards, M. R., Dai, R., Heid, B., Cowan, C. R., Ahmed, S. A.: The effect of dietary phytoestrogen content on the development of systemic lupus erythematosus in the MRL/lpr mouse. J Immunol 196, 118.23 (2016).

46. Pierdominici, M., Ortona, E.: Estrogen impact on autoimmunity onset and progression: The paradigm of systemic lupus erithemotosus. Int Trends Immunol 1, 24-35 (2013).

47. Jin, X., Wang, S., Zhao, X., Jin, Q., Fan, C., Li, J., Shan, Z., Teng, W.: Coumestrol inhibits autoantibody production through modulating Th1 response in experimental autoimmune thyroiditis. Oncotarget 16, 52797-52809 (2016).

48. Tapiero, H., Ba, G. N., Tew, K. D.: Estrogens and environmental estrogens. Biomed Pharmacother 56, 36-44 (2002).

49. Csaba, G.: Hormonal imprinting: Phylogeny, ontogeny, diseases and possible role in present-day human evolution. Cell Biochem Funct 26, 1-10 (2008).

50. Csaba, G.: Immunoendocrinology: Faulty hormonal imprinting in the immune system. Acta Microbiol Immunol Hung 61, 89-106 (2014).

51. Csaba, G.: Hormones in the immune system and their possible role. A critical review. Acta Microbiol Immunol Hung 61, 241-260 (2014).

52. Csaba, G.: The faulty perinatal hormonal imprinting as functional teratogen. Curr Pediatr Rev 12, 222-229 (2016).

53. Csaba, G.: The present and future of human sexuality: Impact of faulty perinatal hormonal imprinting. Sex Med Rev 5, 163-169 (2017).

54. Csaba, G., Inczefi-Gonda, Á., Szeberényi, S.: Lasting impact of a single benzpyrene treatment in pre-natal and growing age on the thymic glucocorticoid receptors of rats. Gen Pharmacol 22, 815-818 (1991).

55. Csaba, G., Karabélyos, C.: Effect of a single neonatal treatment with the soy bean phytosteroid, genistein on the sexual behavior of adult rats. Acta Physiol Hung 89, 463-470 (2002).

56. Csaba, G.: The immunoendocrine thymus as a pacemaker of lifespan. Acta Microbiol Immunol Hung 63, 139-158 (2016).

57. Kovats, S., Carreras, E., Agrawal, H.: Sex steroid receptors in immune cells. In Arthritis and Immunology Research Program. Oklahoma Medical Research Foundation, Oklahoma City, USA, 2009, pp. 53-91.

58. van Hagen, P. M., Holland, L. J., ten Bokum, A. M., Lichtenauer-Kaligis, E. G., Kwekkeboom, D. J., Ferone, D., Lamberts, S. W.: Neuropeptides and their receptors in the immune system. Ann Med 31, 15-22 (1999).

59. Csaba, G.: Is there a hormonal regulation of phagocytosis at unicellular and multicellular levels? A critical review. Acta Microbiol Immunol Hung 64, 357-372 (2017).

60. Tan, I. J., Peeva, E., Zandman-Goddard, G.: Hormonal modulation of the immune system A spotlight on the role of progestogens. Autoimmun Rev 14, 636-642 (2015).

61. Trigunaite, A., Dimo, J., Jorgensen, T. N.: Suppressive effects of androgens on the immune system. Cell Immunol 294, 87-94 (2015). 
62. Seiki, K., Sakabe, K., Kawashima, I., Fuji-Hanamoto, H.: Hormone and immune response, with special reference to steroid hormone. 1. A short review. Tokai J Exp Clin Med 15, 191-199 (1990).

63. Perrotta, C., Buldorini, M., Assi, E., Cazzato, D., De Palma, C., Clementi, E., Cervia, D.: The thyroid hormone, triiodothyronine controls macrophage maturation and functions: Protective role during inflammation. Am J Pathol 184, 230-247 (2014).

64. Pállinger, É., Kiss, G. A., Csaba, G.: Hormone (ACTH, T3) content of immunophenotyped lymphocyte subpopulations. Acta Microbiol Immunol Hung 63, 373-385 (2016).

65. DeVito, P., Balducci, V., Leone, S., Percario, Z., Mangino, G., Davis, P. J., Davis, F. B., Affabris, E., Luly, P., Pedersen, J. Z., Incerpi, S.: Nongenomic effects of thyroid hormones on the immune system cells: New targets, old players. Steroids 77, 988-995 (2012).

66. Csaba, G., Inczefi-Gonda, Á.: Effect of a single treatment (imprinting) with genistein or combined treatment with genistein plus benzpyrene on the binding capacity of glucocorticoid and estrogen receptors of adult rats. Hum Exp Toxicol 21, 231-234 (2002).

67. Csaba, G.: Transgenerational effects of perinatal hormonal imprinting. In Tollefsbol, T. (ed) Transgenerational Epigenetics. Elsevier, London, 2014, pp. 255-267.

68. Csaba, G., Inczefi-Gonda, Á.: Direct and transgenerational effect of benzpyrene treatment at adolescent age on the uterine estrogen receptor and thymic glucocorticoid receptor of the adult rat. Acta Physiol Hung 86, 29-36 (1999).

69. Csaba, G.: The biological basis and clinical significance of hormonal imprinting, an epigenetic process. Clin Epigenetics 2, 187-196 (2011).

70. Karsli-Ceppioglu, S., Ngollo, M., Adjakly, M., Dagdemir, A., Judes, G., Lebert, A., Boiteux, J.-P., Penault-Llorca, F., Bignon, Y. J., Guy, L., Bernard-Gallon, D.: Genome-wide DNA methylation modified by soy phytoestrogens: Role for epigenetic therapeutics in prostate cancer? OMICS 19, 209-219 (2015).

71. Adjakly, M., Ngollo, M., Lebert, A., Dagdemir, A., Penault-Llorca, F., Boiteux, J-P.: Comparative effects of soy phytoestrogens and 17beta-estradiol on DNA methylation of a panel of 24 genes in prostate cancer lines. Nutr Cancer 66, 474-482 (2014).

72. Guerrero-Bosagna, C. M., Skinner, M. K.: Environmental epigenetics and phytoestrogen phytochemical exposures. J Steroid Biochem Mol Biol 139, 270-276 (2014).

73. Csaba, G.: The role of brain-pineal-thymus system in the determination of lifespan: The autoimmune aging theory. Adv Neuroimm Biol 6, 139-148 (2017).

74. Hall, A.: The dark side of soya: How one super crop lost its way? Ecologist, Green living food and drink May 01 (2012). Available at https://theecologist.org/

75. Barnett, A.: They hailed it as a wonderfood. TheGuardian.com, Life and style Nov 07 (2004). Available at https://www.theguardian.com/uk/lifeandstyle

76. Jacobson-Dickman, E., Lee, M. M.: The influence of endocrine disruptors on pubertal timing. Curr Opin Endocrinol Diabetes Obes 16, 25-30 (2009).

77. Marks, K. J., Hartman, T. J., Taylor, E. V., Rybak, M. E., Northstone, K., Marcus, M.: Exposure to phytoestrogens in utero and age at menarche in a contemporary British cohort. Environ Res 155, 287-293 (2017).

78. Martocchia, A., Stefanelli, M., Cola, S., Falaschi, P.: Sex steroids in autoimmune diseases. Curr Top Med Chem 11, 1668-1683 (2011).

79. Csaba, G.: Vitamin-caused faulty perinatal hormonal imprinting and its consequences in adult age. Physiol Int 104, 217-225 (2017). 
80. Tuohy, P. G.: Soy infant formula and phytoestrogens. J Paediatr Child Health 39, 401-405 (2003).

81. Baclottini, L., Falchetti, A., Pampaloni, B., Bartolini, E., Carossino, A. M., Brandl, M. L.: Phytoestrogens: Food or drug? Clin Cases Miner Bone Metab 4, 123-130 (2007).

82. Lambert, M. R., Edwards, T. M.: Hormonally active phytochemicals and vertebrate evolution. Evol Appl 10, 419-432 (2017).

83. Wasserman, J. K.: Estrogenic plants linked to altered hormones, possible behavior changes in monkeys. Science Daily. Available at www.sciencedaily.com/releases/2012/11/ 121119171409.htm

84. Wasserman, M. D., Milton, K., Chapman, C. A.: The roles of phytoestrogens in primate ecology and evolution. Int J Primatol 34, 861-878 (2013).

85. Csaba, G.: Faulty perinatal hormonal imprinting caused by exogeneous vitamin D - Dangers and problems. Aust J Nutr Food Sci 4, 1075-1079 (2016).

86. Tekes, K., Gyenge, M., Hantos, M., Csaba, G.: Transgenerational hormonal imprinting caused by vitamin A and vitamin D treatment of newborn rats. Alterations in the biogenic amine contents of the adult brain. Brain Dev 31, 666-670 (2009). 